Pasi Väliaho: "Animation and the Powers of Plasticity"

Author's final version accepted for publication in animation: an interdisciplinary journal, vol. 12, no. 3, 2017 (SAGE)

Contact details:

University of Oslo

IFIKK

Postboks 1020 Blindern

0315 OSLO

Norway

papeva@utu.fi

Abstract: This article studies the notion of plasticity, which Sergei Eisenstein identified as key to the practice of animation. But rather than approaching plasticity only in aesthetic terms, the article extends its meaning to consider animated figures' power over their beholders. By looking at both historical and contemporary case studies, from Athanasius Kircher's experiments from the seventeenth century to present-day virtual reality applications developed by the US military, the article seeks to understand the transformative potential of animation with regard to psychic life, and how this potential has been turned into a practice of power.

Author biography: Pasi Väliaho is Associate Professor in History of Art at the University of Oslo. He is the author of Biopolitical Screens: Image, Power, and the Neoliberal Brain (MIT Press, 2014) and Mapping the Moving Image: Gesture, Thought and Cinema circa 1900 (Amsterdam University Press, 2010), as well as several journal articles and book chapters. 
Keywords: Plasticity, animation, power, imagination, war, Mickey Mouse, Sergei Eisenstein, Bravemind, Athanasius Kircher, Ignatius of Loyola

\section{Animation and the Powers of Plasticity}

The practice of animation is not only about imparting life to images; it is also about shaping the lives of those that behold them. Besides entertaining or didactic, animations are, in this sense, 'operational'. German artist Harun Farocki observed this sharply while investigating the murkier sides of the contemporary culture of animation in Serious Games (2009-2010), a series of four installations that study the interactive computer-generated environments developed by the US military for drilling recruits, or alternatively for healing soldiers from their traumas. Serious Games shows how digital animations have been enlisted, not merely to tell stories or to please aesthetically, but to mould individuals into the exigencies of armed conflict; how animations have become key operations in the waging of present-day resource wars, operations whereby our psychic life can be unlocked for influence and correction.

The practice of animation, Serious Games tells us, can render ourselves just as supple and programmable as it renders visual forms. This essay takes its cue from Farocki to study the power of animation precisely in the sense of power over the 
plasticity of our minds. The following paragraphs will bring together examples from different historical epochs - from the Jesuit priest Athanasius Kircher's experiments from the late seventeenth century as well as Sergei Eisenstein's musings on Disney from the 1940s to the present-day military applications explored by Farocki - so as to understand the transformative potential of animation with regard to psychic life, and how this potential has been turned into a practice of power. The constellation thus drawn will be outright anachronistic; its method of composition is 'media archaeological' in the sense that it avoids linearity (see e.g., Sobchack 2011). It crosses borders between historical periods just as it traverses from entertainment and religion to the military. Indeed, the following will demonstrate how animations have been variously employed, not only by media moguls, but by army officials and milites Christi alike, and how their targets have been a motley of consumers, believers, pagans as well as servicemen and women. Overall, the concept of animation will be in what follows studied on the fine line between the movement of images on a screen and the movement of images within us, or between technologically animated images and those animated by the psyche. It is on this line, as we will see, that various kinds of practices of government have been operating, by separating one side of the line from the other, or conflating them.

\section{Plasmaticness}

On the 21st of September 1940, whilst at his dacha outside Moscow, Sergei Eisenstein let himself plunge into childhood recollections. A rather haphazard series of scenes emerged from his memory, which the child's mind had animated from 
various literary sources decades earlier: an Arab chased by his crazed camel in the desert; angels descending into hell to soothe suffering sinners; Esmeralda giving water to Quasimodo the hunchback tortured by the crowd in Victor Hugo's 1831 novel. These memories came to him, Eisenstein (1986: 7) explains, as he was watching Walt Disney's Snow White (1937). Eisenstein was fascinated by how Disney's animation allowed its spectators moments of reverie, of inner travel, at which the imagination made a montage of random recollections. But these were above all, as Eisenstein emphasized, moments of oblivion - oblivion from the demands and constrains of the everyday, indeed, moments of 'respite amid the torrential, desperate struggle for life and existence' (Eisenstein 1986: 8).

Reading Eisenstein's unfinished piece on Disney, drafted not long after Soviet Union became involved in the Second World War, one cannot help noticing how it maintains a hint of liberation that allows free play with ideas and impressions - or just a simple transitory feeling of happiness that Disney's characters were able to instigate in the film director. What Eisenstein characterized as 'oblivion' or 'instants of respite' also had, to the author's eye, their visual correlates in animated films themselves. These were, for instance, moments when the hands of a creature like Mickey Mouse could 'stretch far beyond the length allotted to them' (Eisenstein 1986: 10), indeed, moments of transformation that Disney's creatures were particularly capable of (fig. 1). Mickey Mouse, Eisenstein observed, is a being who 'behaves like the primal protoplasm, not yet possessing a "stable" form, but capable of assuming any form and which, skipping along the rungs of the evolutionary ladders, attached itself to any and all forms of animal existence' (Eisenstein 1986: 21). 
$<$ Figure 1. Mickey Mouse's stretching arms. Screen grab from Plane Crazy (Walt Disney and Ub Iwerks, 1928).>

The particularity of animation (as distinct from photography-based cinema), for Eisenstein, was due to its 'plasmatic' nature - 'plasmatic' referring to the ability of animated figures ‘to dynamically assume any form' (Eisenstein 1986: 21). Eisenstein noted how creatures similar to Disney's characters had previously been found, on rare occasion, in literature, most notably in Lewis Carroll's Alice in Wonderland (1865) where Alice grows and/or shrinks depending on what she consumes, or in nineteenth-century Japanese etchings that show the "many-metred arms of geishas reaching out after frightened customers through the gratings of Yoshiwara's teahouses' (Eisenstein 1986: 12). But now these kinds of creatures populated the silver screen (and very soon after the time of Eisenstein's writing, the television screen), creatures who were at any moment susceptible to stretching, bending, and rebounding, if not to total shape-shifting.

If Eisenstein was right, animations did something special: they made movies regress, so to speak, back on the evolutionary scale to the developmental phase where images were flexible and malleable, in a word, plastic, and able to make connections defying the constrains of time and space. If photographic images have had reality as their measure, as their history (and the history of their theory) teaches us (see Silverman 2015), animated images - hand-painted, rotoscoped, what have you - seem to have enjoyed somewhat different cultural and psychological roles and meanings. Eisenstein suggested that the freedom of their form and combinations correlated with the freedom of our imagination (from the constrains of capitalist modes of production, 
according to him), their plasticity with the plasticity of our mental operations. The allusion here is that it is our minds, or, what psychologists call the 'endogenous' rather than the 'exogenous', that are the measure of animations; that it is our dreams and imaginations that animations stem from and attach themselves to. Or perhaps even the opposite is true: that animations are the measure of our minds, and that the transformations of the former may account for transformations of the latter.

\section{Appurtenances of glory}

What Eisenstein called 'plasmaticness' was not historically unique to animated film (see Gunning 2013). Already before the movie machine made its appearance in the late nineteenth century, images themselves had been moving, and whilst moving, enjoying the freedoms of stretching, bending, and transforming. Magic lantern shows were perhaps the longest lasting and most popular and widespread 'ancestors' for animated films in this regard (see Mannoni 2000: 33). Much has been written about the turn-of-the-eighteenth-and-nineteenth century phantasmagoria shows, for instance, where figures appeared and disappeared in the dark as if coming and going as well as growing and shrinking on their own accord, seemingly freed from their technical and material supports (see e.g. Elcott 2016: 78-109).

$<$ Figures 2a-b. Illustrations of the magic lantern from Athanasius Kircher, Ars magna lucis et umbrae, 2nd ed. (Amsterdam, 1671), pp. 768-769.> 
But phantasmagoric animations themselves grew out of a long history of experimentation with optical projections and illusions. Suffice here to highlight one key character who embraced visual plasticity in its multiple forms and functions, the Jesuit priest Athnasius Kircher, who was originally from Germany but spent most of his life as researcher and teacher at the Collegium Romanum, the hotspot of Jesuit science in Rome. Among Kircher's myriad subjects of inquiry, which ranged from hieroglyphs to the earth's formation, was what the polymath in his seminal work Ars magna lucis et umbrae (orig. 1646) called the 'magic of light and shadow' - 'magic' referring to the study of nature's hidden secrets and miraculous effects (Kircher 1671: 673). In this purpose, Kircher developed several ways of projecting and animating visual images by means of refractions and reflections of light. In the second edition of Ars Magna from 1671, the reader encounters, alongside the magic lantern (figs. 2a-b), a 'metamorphosis machine' (or 'proteus catoptricus') and a cylindrical anamorphosis device (fig. 3), a 'smicroscope' (fig. 4), as well as a 'catoptic theatre' (a theatre of reflections).

$<$ Figure 3. Illustrations of the anamorphic device (above) and the metamorphosis machine (below), from Athanasius Kircher, Ars magna lucis et umbrae, 2nd ed. (Amsterdam, 1671), p. 783.>

$<$ Figure 4. Illustration of the smicroscope, from Athanasius Kircher, Ars magna lucis et umbrae, 2nd ed. (Amsterdam, 1671), p. 770.> 
We are familiar with what the magic lantern afforded: figures that, projected in the dark, flickered in front of the viewer's eyes without any apparent cause or anchor, expanding and stretching on conical paths, coming across, as Kircher (1671: 770) described them, as delightful, gloomy, dreadful, frightening, and for those who didn't know what caused them, even monstrous. Crucially, in the discursive space of Jesuit scholarship, these animations couldn't be separated from other machines of illusion as well as immersion. Whilst the 'catoptic theatre', a box of mirrors that multiplied the objects put in it, was able to so amaze 'the viewers that they try in vain to touch what they see inside it' (Godwin 2009: 210), the smicroscope presented a sequential way of looking at separate images, or scenes, that became industrialized by the movies. Whilst cylindrical anamorphosis conjured figures hanging in the air, the 'metamorphosis machine', at least allegedly, finally achieved the transformation of the beholder's self-image in the mirror with the head of a donkey, deer or hawk, or whatever was painted in the drum that remained invisible to the viewer (Kircher 1671: 782; see Godwin 2009: 213).

Sudden appearances, multiplications, movements, and transformations - these were the attributes of the images thus contrived. It is here that we can locate an example of the early developmental stages of animated images, which Eisenstein referred to as 'plasmaticness', indeed, the dynamic shifting of forms, not least the observer's own appearance. And it is here that, in terms of the history of technical images, we see the genealogy of what Tom Gunning (2013: 56) calls the 'fantasy of metamorphosis or the potential for transformation' that has been a key defining characteristic of animation in its multiple manifestations. 
Yet wasn't the 'monstrous variety of apparitions' that Kircher (1646: 905) wanted to conjure with his machines fundamentally an experiment on the malleability and mutability of the beholder's perceptions and imaginations rather than merely of visual images? At least, what is crucial is that Kircher's devices destabilized separations between inner images and external ones, between what the psyche produces from within and what sifts through to perception from without. The products of a magic lantern or a metamorphosis machine were devised to mesh with the products of our own bodies and minds - dreams, memories, imaginations, hallucinations, etc. Such transformations and metamorphoses spoke of a visual experience in crisis. In the early modern period, Stuart Clark argues, 'in one context after another, vision came to be characterized by uncertainty and unreliability, such that access to visual reality could no longer be normally guaranteed' (2007: 2). This was a crisis of what can be trusted and what not - or, more accurately perhaps, a crisis concerning who has the power to determine the parameters of reality.

In this sense, the crisis in visuality exemplified by Kircher's 'transformationimages' was especially of a religious kind, and as such a symptom of deeper rifts in the mental economies that partitioned seventeenth-century Europe. It had started over a century earlier when the followers of Martin Luther, John Calvin and others challenged the authority of the Catholic Church on matters spiritual, theological as well as visual. Henceforth, a war on the souls of populations was battled, not only with swords and gunpowder, but also with words and images. Without going into the complex media history of the reformation struggles, which involved the print press, songs, pamphlets, woodcuts, etc., suffice to note that the Protestants had, if not banned the worship of images, turned it into a private matter. The soul and its 
passions and animations had to be unmoored from their traditional appurtenances such as murals, paintings, relics, sculptures and imposing ceremonies; they needed to be purged of such 'phantoms and delusive shows', to borrow Calvin's words (Eire 1986: 226).

So-called catholic counter-reformation, to put it bluntly, responded by creating ever more sensuous spectacles and ever more delusive shows, by augmenting the effectiveness of all sorts of phantoms as vessels of belief (see Levy 2004). Heading these operations were the knights of the Jesuit Order whose importance in the development of counter-reformation culture was pivotal. Instead of whitewashing church walls of illustrations and ornaments, more and more spectacular architectures of worship were built under the Jesuits' direction, where trompe-l'oeil pictures and special effects of light and shadow, among other things, created illusionistic spaces that connected the earthly realm with the divine. Crucial here was the art of immersion, akin to contemporary virtual reality, according to some (Burda Stengel 2006: 105). The frescoes painted by the Jesuit artist and architect Andrea Pozzo in the Sant'Ignazio Church in the late seventeenth century, for instance, blended the real and the fictional space in perception to the extent that they were able to give rise to the 'miracle' of the earthly transforming into the divine in the spectator's experience (Burda Stengel 2006: 76-101). The Jesuits, that is to say, fought back with miracles and fictions designed for administering and moulding the products of the imagination.

Kircher's work on optical machines may seem of less importance and perhaps even effectiveness, but it was at least symbolically highly relevant to counterreformation operations (see Kittler 2010: 72-81). Kircher was, we recall, a lifetime member of the Society of Jesus, and one of its venerated scholars, who worked at the 
very heart of the Catholic system of power. 'Faith must be one, holy and Catholic, conforming to the Church which is the firmament of truth,' he once wrote (Godwin 2009: 31). The rules of the Jesuit order, the constitutiones, urged him specifically to 'fight for God under the banner of the cross' (Mayer-Deutsch 2008: 245). The optical machines were aimed to be 'evocative' of inner visions and imaginations of all kinds in service of this rule. The illustrations in particular let us work out how the devices became embedded within the tradition and practices of Jesuit culture of training and persuasion. The famous drawings of the magic lantern show the apparatus (even if not properly arranged) projecting the grim reaper with an hourglass, as well as a person burning in the flames of hell. The smicroscope conjured a scenario of the Passion of Christ in a proto-movie, whilst by means of the cylindrical anamorphosis device, Kircher asserted, one was able to portray the Ascension of the Lord so vividly that the figures seemed to be hanging in mid-air (Kircher 1671: 770, 781). Life, passion, death and the resurrection of the Christ - these were also key materials of the spiritual exercises that the founder of the Jesuit Order, Ignatius of Loyola had come up with in the early sixteenth century as a sort of manual of mental drills. Different scenes on the slide disk of the smicroscope, for instance, replicated the contents of the third week of the exercises, which focuses on visualizing the Passion (see Mayer-Deutsch 2008: 252). Likewise, the illustrations of the magic lantern projections appear to reproduce the fifth exercise of the first week, the 'meditation on hell' (see Kittler 2009: 78-80):

The first prelude is the composition of place. Here it will be to see in imagination the length, breadth, and depth of hell. 
The second prelude is I will ask for what I desire. Here it will be to ask for a deep awareness of the pain suffered by the damned, so that if I should forget the love of Eternal Lord, at least the fear of punishment will help me to avoid falling into sin.

1st. The first point is to see with the eye of the imagination the great fires, and the souls enveloped, as it were, in bodies of fire.

2nd. The second point is the hear the wailing, the screaming, cries, and blasphemies against Christ our Lord and all His saints. (Ignatius de Loyola 1986: 119)

And so on. Loyola's exercises encompassed all the five senses, from vision and hearing to touch, taste and smell. But above all, they were targeted for training novices into members of the Society by controlling how and what one is capable of 'seeing with the imagination's eye' (ibid. 116). The arrangement of these drills resembled the situation of entering the magic lantern projection room designed by Kircher (figs. 2a-b). 'I will deprive myself of all light, closing the shutters and doors when I am in my room,' the exercises suggest in the first person (ibid. 121). In the dark of this artificial night, the mind's production of sensations, appearances and scenarios could begin. The spiritual exercises were first and foremost an exercise on the powers of imagining: 'Imagine Christ our Lord before you, hanging upon the cross. Speak with Him of how from being the Creator He became man, and how, possessing eternal life, He submitted to temporal death to die for our sins' (ibid. 117). But furthermore, the exercises were aimed at divesting the exercitant's memory of its habitual contents - at making one forget through the concentrated repetition of select 
imagery (Fabre 1992: 85-88). In this way, as Ignatius pointed out, the spiritual exercises were 'methods of preparing and disposing the soul' for 'the glory of God our Lord' (Ignatius de Loyola 1986: 105, 138), methods, to put it otherwise, of administering and regulating the individual's inner production of dreams, imaginations and remembrances, that is, the soul's animations and passions.

As Roland Barthes observed, the 'I' that the exercises call forth 'has absolute plasticity: it can transform itself, reduce itself according to the needs of the comparison - "Consider who I am and make myself smaller and smaller through comparisons with (a) other men, (b) the Angels, (c) God"” (Barthes 1989: 64). Such a practice of shaping the psyche and its potentials of transformation found its technological counterparts, at least metaphorically speaking, in Kircher's optical machines. The metamorphosis machine presented a rather literal visual translation of the ego's proneness to shape shifting (fig. 3). The magic lantern, on the other hand, implemented the workings of the imagination, as Friedrich Kittler asserted: 'Thanks to the lanterna magica the solitary hallucination of the founder of the Jesuit Order, who once concentrated all his five senses on imagining the agonies of hell, became technologically simulated for the masses' (2010: 80). Likewise, one might conceive of the serial presentation of scenes from the Passion in the smicroscope (fig. 4) not merely in terms of the literal movement of pictures in front of one's eyes, but also in terms of the 'movement and expansion of the psyche' (Mayer-Deutsch 2008: 252). And one can just as well conjecture how seeing the Christ ascending in mid-air in the cylindrical anamorphic device (fig. 3) approximated with hallucinating the event in solitary confinement... Thus, the 'fantasy of metamorphosis' that, according to Gunning, has breathed life into images for centuries, has been an anthropologically 
complex once. It has concerned just as much figures moving on a screen (or otherwise) as those beholding them. Like the Jesuit exercitant in his dark cell, the beholder of technologically projected and animated images was meant to undergo a series of modifications and adjustments of what she or he can imagine, think, and recollect.

Here we encounter an idea of plasticity that is, curiously enough, not so far removed from Eisenstein's musings from a couple of centuries later. In his cinematic and theoretical work, we remember, Eisenstein concentrated on seeking parallels between cinema and the spectator's mental life with the aim of engineering experience. One wonders, in this regard, why Eisenstein didn't mention Kircher in his essay draft on Disney. Kircher, like Eisenstein, celebrated transformation over the stability of form; and Kircher, like Eisenstein, experimented with various visual techniques by means of which one could shape people's mental imagery. At least, Eisenstein had read in Terry Ramsaye's history of the seventh art from 1926, $A$ Million and One Nights, how 'through Kircher we see the pictures become liberated from the immobility of paint and canvas' (Ramsaye 1926/1986: 7; see Albera 2016: 273). This liberation from being to becoming was precisely what Eisenstein admired in Disney. At stake, of course, in Eisenstein's musings was the revolutionary potential of images, rather than the Jesuit Order's reactionary mission for converting and managing souls. But Knights of the Jesuit Order, we should keep in mind, wanted to embrace and enlist transformational drives just as much as Soviet revolutionists did.

The exploits of the Jesuits suggest how animation, significantly, has its historical roots as a governmental practice - a practice of shaping souls by rendering them as plastic and pliable. The concept of government, we recall, has its background 
in the Greek oikonomia, that is to say, economy (Agamben 2011). In the case of animation, we can speak of a specific kind of visual economy destined for the management of psychic realities. A further example of such comes from the 1646 edition of Ars Magna where Kircher noted that by drawing 'a devil's form' onto a mirror and projecting it into a dark place, one can easily prevent 'impious people' from committing wicked deeds (Kircher 1646: 912). If one is able to prevent somebody from doing something by means of projections and animations in the dark, the reverse is also true: images can be used to regulate behaviour, at least indirectly by projecting 'emotional effect' and exerting 'pressure' on the psyche, as Eisenstein (1988: 46) put it early in his career. The medium for this kind of government of the soul was, as noted, the imagination. We are not necessarily talking here about the imagination of the 'moderns' susceptible to deceiving and to misguiding, wilfully or not. We are rather talking about the imagination as presiding over what can be considered right and wrong, sacred and not. As Gilbert Simondon (2008: xxxi) observed (in his lectures from the 1960s), the imagination can be understood as 'a function of the real, of realization'. It is precisely in this sense that the imagination has been (and still is, one could argue) the subject-object of struggles for and against power.

\section{Brave minds}

The Ignatian exercises, as Barthes noted, were framed from the first-person viewpoint: 'This theater [of imagination] is entirely created in order that the exercitant may therein represent himself: his body is what is to occupy it' (Barthes 1989: 63). 
The subject is there, present to the scene conjured up - descending the purgatory, burning in flames, climbing a mountain... Not only his self but his body, too, is invested in the scene. From today's viewpoint, the most accurate media technological analogy for the exercises in this sense is not the movies, theatre or even the magic lantern, but rather a video game or a virtual reality device. It is the latter that since the 1970s or so have afforded bodily presence and action (literally, in sensorimotor terms) in virtual and fictional realms.

This analogy might of course appear as helplessly misplaced in its anachronistic generality, yet focusing on practices of government and their genealogies could make it more clear and concrete. In this respect, it is not the mass media of entertainment - say, the billion-dollar business that video games industry is today - that give us the most vivid examples, but rather the context of what is called 'serious games', which this essay kicked off with: virtual reality applications developed, among other things, for the purposes of training and/or therapy on both sides of the border that divides between military and civilian life, or between what is called normal and what is called pathological. These applications take us from the public (or, publically private) spectacles of power that video games represent to the back rooms of governmental operations, where experiments of a more decisive nature are made.

Bravemind is a new instalment in the series of virtual reality environments developed by scientists, clinicians, artists and engineers, and funded by the US Army, for the treatment of post-traumatic stress disorder amongst veterans and combatants of wars fought over the globe currently. It builds on earlier models of VR-based psychotherapy called Virtual Iraq and Virtual Afghanistan developed in 2005-2007, 
enhancing their contents and introducing more affordable technology. With the current model, a range of different kinds of 'generic' scenes can be contrived:

The four original 2007 environments have been completely rebuilt and ten additional scenarios have been added for a total of 14, including: separate Iraq and Afghanistan cities, a rural Afghan village, an industrial zone, a roadway checkpoint, slum and high-end residential areas, a mountainous forward operating base, and a Bagram Air Force Base setting. New features include selectable Humvee/MRAP/Helicopter vehicles, vehicle-to-foot patrol transitioning, expanded weather and time of day controls, customizable sound trigger profiles, and an updated clinical interface designed with clinician feedback to enhance usability. (Rizzo et al. 2015: 258)

The biblical settings of counter-reformation visuals have become more mundane, whilst projected images have turned into computer-generated animations presented within a head-mounted display that tracks the viewer's movements. Scenarios like above are evoked to treat traumatized individuals suffering from flashbacks and fears (fig. 5). Holding a mock rifle in their hands and wearing a headset, patients are transported into virtual environments that resemble the locations of their traumas. Images, sounds, even smells are conjured that model the traumatic event according to the patients' verbal accounts - these 'cues' are produced and controlled in the course of the treatment session by the therapist, who operates an interface called 'Wizard of Oz' (a somewhat contentious reference to Victor Fleming's 1939 film, which associates the therapist with the Wizard in the film who is revealed to be a mere 
trickster of appearances).

$<$ Figure 5 . Bravemind scenario. Screenshot from a promotional video by University of Southern California Institute of Creative Technologies, 2014 (source: https://www.youtube.com/watch?v=LRL0TzrNtVc.>

Again, as about 400 years earlier, we are dealing with the technological shaping of capacities of visualization, indeed, of 'the imagination's eye' and, consequently, the soul's passions and animations. And as about 400 years earlier, this shaping is part of a militant quest for planetary rule over resources and populations. The specific reasons for having recourse to a virtual reality device instead of more traditional therapeutic methods (such as 'exposure therapies' relying on the person's spontaneous capacities of imagination only) relates precisely to this pursuit's legitimization in the imaginary. Some 'clients' (as the neoliberal neologism goes) are 'unwilling or unable to effectively visualize the traumatic event' in the therapy session; that is to say, they refuse to 'emotionally engage (in imagination)' with their past (Rizzo et al. 2015: 257). But by immersing individuals into a virtual reality environment, the developers argue, this kind of resistance can be defeated.

The efficacy, if you will, of virtual reality simulations hinges on the individual's readiness to comply and to adjust when transported (in a gradual manner over the course of several therapy sessions) back into their intimate nightmares via technologically produced triggers. The efficacy, in other words, relies on the individual's powers of plasticity in the sense of the ability to receive form, as well as to change form, whilst being emotionally pressured within the VR environment. We 
remember how Eisenstein imagined cinema's key vocation in such terms; however, today's science talks in particular about neural plasticity, referring to the management of mental events in terms of the coding of the brain's physiology, which has become the defining characteristic of subjectivity currently (Malabou 2008; Väliaho 2014: 8284). But also old concepts like the imagination are still able to capture the essential. Let us quote a 'Virtual World Trade Center Case Report':

As [David] habituated to stimuli, the therapist began to match the elements of his experience more closely. He was placed in the virtual environment at closer proximity to the towers as he had been on that day, and auditory and visual elements were added to reflect his experience. The towers were shown with gaping holes in flames, accompanied by sounds of screams and fear. As he described seeing the South Tower collapse, the virtual environment displayed the South Tower crumbling, accompanied by the rumbling sound, as he was virtually overrun by the dust cloud. Slowly he habituated to each of the sensory elements as well. (Rizzo et al. 2015: 262)

Thus, remembrances become (at least in appearance) tamed and the intensities of emotions reduced through 'habituation'. By reproducing and recycling mental imagery in the form of computer-generated animations, what is being managed and shaped is, first and foremost, how one is able to relate to one's past and thereby to oneself. 'Trauma, triggers, and therapy remain in the physical or virtual worlds as war zones, which do not offer an alternative perspective for patients', Kathrin Friedrich (2016: 104) points out about virtual reality therapy. The question, as Friedrich 
suggests, concerns here, at least partially, how the conditions of imagining become defined - how the powers of the imagination to give birth to ourselves and the reality around us are administered by turning unruly images into abiding materials of accepted narratives and symbolizations.

Ignatian exercises, Barthes (1989: 69) emphasized, were designed to restore and improve the individual's capacities of fashioning their fantasies by 'filling the spirit with images'. Bravemind, one might argue, is based on a similar design. The technology shapes and qualifies the individual - 'inoculating' them against stress and fear, in particular - by determining what kinds images their minds are animated by, and with what levels of intensity. The Jesuits' techniques for the management of souls thus reappear like ghosts from a time now forgotten in Bravemind's set-up: the common aim is to cast out certain "fleeting images that invade the spirit like "a disorderly swarm of flies"”, to quote Barthes (1989: 69). Ordering images into orthodoxy; this is achieved by means of verbalization and narration whereby language takes hold of and contains the psyche's at times explosive imaginative potential. In this way, the virtual reality platform comes across as a perfect illustration of contemporary procedures for managing the individual's potentials of transformation, especially in terms of depoliticizing the imagination (see Brandt 2016).

From Mickey Mouse's stretching arms to bombs exploding and towers in flames, or alternatively, crucifixions and souls burning in the Purgatory - through various detours, we have made a long way on the perhaps less well trodden paths of 
animation's history to make sense of the form's peculiar plasticity. Inspired by Disney's cartoons, Eisenstein suggested that the plasticity of animated figures, liberated from the constraints of the real, could correlate with the plasticity of our psychic life, with our mind's capacity to both receive and create form. But we have also seen how the instances of oblivion and the flights of imagination afforded by animation have historically and today had rather different kinds of roles and functions than Eisenstein had in mind. They have become 'operational' in the sense of tools of power designed for particular effects. From Kircher's experiments with his optical devices we learned that beholding animations and other kinds of visuals could be considered a disciplining exercise on the soul's phantasmatic material akin to Ignatius of Loyola's drills on the imagination and memory. Animation meant here (to put it in cybernetic terms) a self-regulatory practice whereby the psyche learned what kind of imagery it was to subscribe to. Such self-regulation has been put further into operation in today's virtual reality applications where computer-generated animations (alongside verbalization) effectively modulate, manage and balance the mind's production of images in view of rehabilitation and 'rehabituation'. Animation's liberation from the real, this historical juxtaposition suggests, means that it is liberated to take hold of our power of the imagination as a function of the real.

But as what kind of a function? Stanley Cavell once noted about animated creatures such as Disney's:

Beasts which are pure spirits, they avoid, or deny, the metaphysical fact of human beings, that they are condemned to both souls and bodies. A world whose creatures are incorporeal is a world devoid of sex and death, hence a 
world apt to be either very sad or very happy. (Cavell 1979: 171)

Cavell's estimation coincides with Eisenstein's. Namely, what else is the capacity of animated figures 'to dynamically assume any form' than metaphysical avoidance or denial of corporeality? Don’t Mickey's limbs stretch and bend beyond proportion precisely to avoid the thickness of flesh and, fundamentally, the very finitude of existence? Mickey survives the severest of plane crashes; he rebounds after every explosion. There is nothing that can destroy him. The game is never over. Should we then proceed to infer that 'operational animations' - animations that serve governmental goals - also commit to such a denial of finitude? One may indeed wonder what else animations of burning bodies and towers do than seek to repress the nagging feeling of one's metaphysical limitations, thereby bending the real into a play as well as a battleground of fantasy - a fantasy, not only of metamorphosis, but crucially, of omnipotence. Thus, in their pursuit of the dream of infinite power, they create a here-and-now that is very sad indeed.

\section{Bibliography}

Agamben G (2011) The Kingdom and the Glory. Trans. Chiesa L. Stanford: Stanford University Press. 
Albera F (2016) 'The Heritage We Renounce': Eisenstein in Historio-Graphy. In:

Eisenstein S, Notes for a General History of Cinema. Ed. Kleiman N \& Somaini A. Amsterdam: Amsterdam University Press, pp. 267-288.

Barthes R (1989) Sade, Fourier, Loyola. Trans. Miller R. Berkeley: University of California Press.

Brandt M (2016) 'Simulated War: Remediating Trauma Narratives in Military Psychotherapy'. Catalyst: Feminism, Theory, Technoscience 2(1): n.p. Available at: catalystjournal.org/ojs/index.php/catalyst/article/view/brandt/172

Burda Stengel F (2006) Andrea Pozzo et l'art vidéo: Déplacement et point de vue du spectateur dans l'art baroque et l'art contemporain. Trans. Wagner H. Paris: Isthme éditions.

Cavell S (1979) The World Viewed: Reflections on the Ontology of Film. Enlarged ed. Cambridge, MA: Harvard University Press.

Eire C (1986) War Against the Idols: The Reformation of Worship from Erasmus to Calvin. Cambridge: Cambridge University Press.

Elcott N (2016) Artificial Darkness: An Obscure History of Modern Art and Media. Chicago: Chicago University Press. 
Eisenstein, S (1986) Eisenstein on Disney. Trans. \& ed. Leyda J. Seagull Books.

Eisenstein, S (1988) Montage of Film Attractions. In: Eisenstein S, Selected Works, vol. 1: Writings, 1922-34. Trans. \& ed. Taylor R. London: BFI, pp. 39-58.

Fabre P-A (1992) Ignace de Loyola, le lieu de l'image: Le problème de la composition du lieu dans les pratique spirituelles et artistiques jésuites de la seconde moitié XVIe siècle. Paris: Vrin.

Friedrich K (2016) Therapeutic Media: Treating PTSD with Virtual Reality Exposure Therapy. MediaTropes 6(1): 86-113. Available at:

www.mediatropes.com/index.php/Mediatropes/article/view/27102

Godwin, J (2009) Athanasius Kircher's Theatre of the World. London: Thames \& Hudson.

Gunning T (2013) The Transforming Image: The Roots of Animation in Metamorphosis and Motion. In: Buchan S (ed) Pervasive Animation. New York: Routledge, pp. 52-67.

Ignatius de Loyola (1986) Powers of Imagining. Albany: SUNY Press.

Kircher A (1646) Ars Magna Lucis et Umbrae. Rome: Hermann Scheus. 
Kircher A (1671) Ars Magna Lucis et Umbrae. 2nd ed. Amsterdam: Joannes

Janssonius Waesberg \& heirs of E. Weyerstraet.

Kittler F (2010) Optical Media: Berlin Lectures 1999. Trans. Enns A. Cambridge: Polity.

Levy E (2004) Propaganda and the Jesuit Baroque. Berkeley: University of California Press.

Malabou C (2008) What Should We Do with Our Brain? Trans. Rand S. New York: Fordham University Press.

Mannoni L (2000) The Great Art of Light and Shadow: Archaeology of the Cinema. Trans. Richard Crangle. Exeter: University of Exeter Press.

Mayer-Deutsch A (2008) The Ideal Musaeum Kircherianum and the Ignatian Exercitia spiritualia. In: Schramm H, Schwarte L and Lazardzig J (eds) Instruments in Art and Science: On the Architectonics of Cultural Boundaries in the $17^{\text {th }}$ Century. Berlin: Walter De Gruyter, pp. 235-256.

Ramsaye T (1926/1986) A Million and One Nights: A History of the Motion Picture through 1925. New York: Simon \& Schuster.

Rizzo A et al. (2015) Virtual Reality Exposure for PTSD Due to Military Combat and 
Terrorist Attacks. Journal of Contemporary Psychotherapy 45(4): 255-264.

Silverman K (2015) The Miracle of Analogy or The History of Photography, Part 1. Stanford: Stanford University Press.

Simondon G (2008) Imagination et invention (1965-1966). Chatou: Editions de la Transparence.

Sobchack, V (2011) Afterword: Media Archaeology and Re-presencing the Past. In Huhtamo E \& Parikka J (ed) Media Archaeology: Approaches, Applications, and Implications. Los Angeles: University of California Press, pp. 323-333.

Väliaho P (2014) Biopolitical Screens: Image, Power, and the Neoliberal Brain. Cambridge, MA: MIT Press. 